\title{
Mulheres jornalistas esportivas e mercado de trabalho: quem (não) as deixa trabalhar?
}

\author{
Lídia Ramires ${ }^{1}$ \\ httts://orcid.org/0000-0003-3456-4341 \\ ${ }^{1}$ Universidade Federal de Alagoas, Curso de Jornalismo, Maceió, AL, Brasil
}

\section{Mulheres jornalistas esportivas e mercado de trabalho: quem (não) as deixa trabalhar?}

Resumo: O artigo analisa o discurso das mulheres jornalistas esportivas brasileiras que, a partir do manifesto \#DeixaElaTrabalhar se reúnem em coletivo para denunciar situações de assédio e violência sofridos no exercício profissional. Mesmo após mais de um século de coberturas realizadas por mulheres que comprovam competência, habilidade e condições profissionais, o jornalismo ainda é um campo de discriminação e sexismo, em nível mundial. A editoria de Esportes é ainda marcada pela presença masculina e o desafio das mulheres ainda é de luta por espaço e oportunidades. A equidade entre homens e mulheres pregada pelo discurso jurídico ainda está distante da prática verificada por essas profissionais que demandam o direito de trabalhar.

Palavras-chave: Trabalho. Discurso. Gênero. Jornalismo. Esporte.

\section{Women sports journalists and labor market: who (not) lets them work?}

Abstract: The article analyzes the discourse of women Brazilian sports journalists who, from the hashtag \#DeixaElaTrabalhar meet in collective to report situations of harassment and violence suffered in professional exercise. Even after more than a century of coverage by women who prove competence, skill and professional conditions, journalism is still a field of discrimination and sexism worldwide. The sports in journalism is also marked by the masculine presence and the challenge of women is still fighting for space and opportunities. The equity between men and women preached by legal discourse is still far from the practice verified by these professionals who demand the right to work.

Keywords: Labor. Discourse. Gender. Journalism. Sport.

Recebido em 18.02.2020. Aprovado em 15.04.2020. Revisado em 26.05.2020.

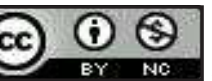

(C) O(s) Autor(es). 2020 Acesso Aberto Esta obra está licenciada sob os termos da Licença Creative Commons Atribuição-NãoComercial 4.0 Internacional (https://creativecommons.org/licenses/by-nc/4.0/deed.pt_BR), que permite copiar, distribuir e reproduzir em qualquer meio, bem como adaptar, transformar e criar a partir deste material, desde que para fins não comerciais e que você forneça o devido crédito aos autores e a fonte, insira um link para a Licença Creative Commons e indique se mudanças foram feitas. 


\section{Introdução}

Este trabalho é um recorte da pesquisa desenvolvida no pós-doutoramento, na Universitè de Toulouse, junto ao Laboratoire d'Études et de Recherche Appliquées em Sciences Sociales, que analisa o discurso de mulheres jornalistas esportivas brasileiras, a partir do manifesto \#DeixaElaTrabalhar, com denúncias de casos de assédio moral e sexual no ambiente de trabalho, a luz do referencial teórico-analítico da Análise do Discurso de linha francesa.

Neste texto, interessa-nos refletir, mais especificamente, sobre as condições das mulheres no mercado de trabalho no Brasil, traçando paralelo com pesquisas pelo mundo que denunciam que, mesmo após 130 anos da viagem recordista de Nelly Bly ${ }^{1}$ - que percorreu sozinha mais de 40 mil quilômetros, em quatro continentes, dando uma volta ao Mundo em 72 dias, em 1890 (GOODMAN, 2013) - cada mulher jornalista ainda precisa reiterar sua capacidade de trabalho, provando diariamente que o mérito profissional não é sempre o que lhes é avaliado por colegas, empregadores, chefes e público.

Notadamente um dos campos ainda mais misóginos do fazer jornalístico está na editoria de Esportes de revistas, jornais, portais na internet, programas de rádio, TV ou canais na Web. Uma vez que o esporte de maior destaque e cobertura jornalística no país é o futebol, a situação se torna ainda mais sexista, afinal: futebol não é coisa de mulher.

A tradicional bola branca e preta é marcante em estampas de roupas de bebês e crianças (meninos), é o presente que muitos garotos recebem, já na mais tenra idade - aqueles que por falta de condições financeiras não têm acesso aos brinquedos industrializados, recorrem a tiras de tecido velho para a confecção das tradicionais bolas de meia. Em oposição socialmente automatizada às bonecas para as meninas, estão às bolas para os meninos. E a naturalização sai das casas e ganha às ruas, escolas, campinhos de várzea, quadras de futsal e os gramados, amadora e profissionalmente.

A prática de esportes é estimulada para meninos, com destaque para competições e premiações; enquanto às meninas, as atividades destacadas são mais ligadas ao "feminino", à arte e ao belo. Não à toa, as escolinhas de futebol são majoritariamente ocupadas por garotos, enquanto as classes de balé recebem as garotas. A inversão de participantes dessas turmas, mesmo no século XXI, causa estranhamento e assim, a lógica de que existem espaços, cores, tarefas e profissões exclusivos para homens e mulheres reforçada ${ }^{2}$.

As mulheres deverão ser notícia, produzir notícia, redigir notícia, narrar, reportar, apresentar e comentar eventos das mais

diversas abordagens. Deverão ter a liberdade (direito democrático) de serem quem são, como assim nasceram, como tenham se constituído social e politicamente, como escolheram ou como foram chamadas a viver. A luta só se amplia com a tomada de pautas de grupos de invisibilizadas - sejam elas negras, indígenas, lésbicas, trans... enfim, mulheres. Longe de ser algo novo, como diz acreditar a ministra Damares Alves ('MENINO veste azul e menina veste rosa', diz Damares Alves, 2019), o Brasil permanece com a discriminação às mulheres em postos de trabalho, seja no Jornalismo e, de forma ainda mais destacada, no Jornalismo Esportivo.

São discursos que reforçam a lógica da divisão sexual do trabalho ${ }^{3}$, resultante das relações determinadas social e historicamente, que hierarquizam as funções - sempre valorando como superior o trabalho dos homens - e separam, claramente, o que é trabalho de homem e o que é trabalho de mulher. Segundo SouzaLobo, "a divisão social do trabalho produz e reproduz a assimetria entre práticas femininas e masculinas, constrói e reconstrói mecanismos de sujeição e disciplinamento das mulheres, produz e reproduz a subordinação do gênero dominação" (SOUZA- LOBO, 2011, p. 174).

\section{Da proibição legal à interdição velada no mercado de trabalho: obstáculos e teto de vidro}

Esportes considerados “masculinos” tiveram a prática proibida a mulheres, no Brasil, por lei do Governo Getúlio Vargas - dentre eles o futebol - e permaneceu vigente até 1983. Segundo o Decreto-Lei n. 3.199 de 14 
de abril de 1941, “às mulheres não se permitirá a prática de desportos incompatíveis com as condições de sua natureza, devendo, para este efeito, o Conselho Nacional de Desportos baixar as necessárias instruções às entidades desportivas do país" (BRASIL, 1941). A proibição das práticas e, consequentemente, a ausência de profissionalização têm, segundo Silva (2017), reflexos negativos até hoje, como o pouco incentivo às práticas e o baixo investimento de patrocinadores.

Se a lista de esportes proibidos colocou as mulheres por quatro décadas longe do profissionalismo como atletas, a dificuldade no exercício do jornalismo esportivo permanece, mundialmente, como explica Schoch:

No esporte, assim como em outros domínios como a política ou a guerra, que são pensados como "masculinos" [...] permanecem globalmente bastiões masculinos dos meios de comunicação em muitos países [...] particularmente, no caso dos esportes de tradição masculina, como o futebol, o basebol ou o hóquei no gelo. (SCHOCH, 2019, p. 31) .

Em estudo publicado por Lucie Scoch e Fabien Ohl reúne pesquisas que mostram que, desde a década de 1990, a presença de jornalistas mulheres nas redações tem crescido dramaticamente mas, "o número de mulheres que entraram no jornalismo esportivo, um tradicional domínio masculino, é menor e permanece sendo domínio-masculino"5 (2011, p. 190). O estudo avaliou dados coletados sobre profissionais nos Estados Unidos, França, Holanda, Suécia e Suíça (SCHOCH; OHL, 2011).

No Brasil, o levantamento mais atualizado sobre a presença feminina no mercado de trabalho é o relatório da pesquisa Mulheres no jornalismo brasileiro, realizada pela Associação Brasileira de Jornalismo Investigativo (Abraji), pela consultoria Gênero e Número, em parceria com o Google News Lab, com o objetivo mapear o assédio às profissionais de imprensa, por fontes de informação e nas redações. O estudo, inédito no País, se deu a partir de entrevistas com grupos focais de jornalistas em São Paulo, Brasília, Rio de Janeiro e Porto Alegre, e de um questionário mais abrangente, que respondido por 477 profissionais que atuam em 271 veículos diferentes. (ASSOCIAÇÃO BRASILEIRA DE JORNALISMO INVESTIGATIVO, 2017).

A pesquisa indicou que $83,6 \%$ das mulheres consultadas já sofreram algum tipo de violência psicológica, $65,7 \%$ já tiveram sua competência questionada e $64 \%$ já sofreram abuso de poder de chefes ou fontes de informação. Outros $86 \%$ das mulheres que responderam o questionário afirmaram já terem vivenciado algum tipo de discriminação de gênero no trabalho, quanto a oportunidades de crescimento profissional, distribuição de tarefas ou definição de salários (ASSOCIAÇÃO BRASILEIRA DE JORNALISMO INVESTIGATIVO, 2017).

Os dados indicaram ainda que apenas 4,6\% das respondentes têm Esportes como principal editoria de desempenho de suas funções. A situação se mostra ainda mais alarmante quando a divisão do trabalho encontra as regras cristalizadas na estereotipificação de posições que se acentuam nos casos de chefia (editores) numa situação de teto de vidro em que, embora invisível, há uma barreira que impede a ascensão profissional de mulheres, apenas por serem mulheres - como explica o relatório:

O que encontramos de discrepante são as áreas de esportes, educação e tecnologia, nas quais os homens estão sobre-representados como editores. [...] Já na área de turismo, moda, gastronomia e estilo de vida há proporcionalmente mais mulheres editoras que homens. Esse quadro sugere uma certa divisão do trabalho jornalístico conforme os antigos estereótipos. (ASSOCIAÇÃO BRASILEIRA DE JORNALISMO INVESTIGATIVO, 2017, p. 16-17).

Dentre os relatos de assédio e discriminação sofridos por mulheres jornalistas, o relatório traz, ainda em sua apresentação, o caso de uma repórter que, em setembro de 2017, ouviu do técnico do Sport Club Internacional, ao questionar a atuação do time: "Desculpe, eu não vou fazer essa pergunta para você porque você é mulher e de repente não jogou (futebol)". (ASSOCIAÇÃO BRASILEIRA DE JORNALISMO INVESTIGATIVO, 2017, p. 6-7, grifo nosso).

O funcionamento discursivo produz o efeito de evidência de que sendo mulher não é capacitada para debater questões técnicas de um esporte amplamente veiculado, comentado, estudado e sob sua atuação profissional - uma vez que estava presente na cobertura do jogo, portanto, habilitada pela Associação de Cronistas Esportivos do Rio Grande do Sul, credenciada pela Federação de Futebol do estado, além de contratada por um veículo de comunicação. Há que se questionar se todos os repórteres envolvidos numa transmissão tiveram atuação como atletas e se suas capacidades também são postas em dúvida a cada pergunta proferida.

Como aponta Orlandi (2012, p. 27-8), "o discurso é efeito de sentidos entre locutores e isto acarreta toda uma declinação teórica do que é sujeito, do que é sentido, do que é memória, do que é história, do que é sociedade, do que é ideologia, do que é língua, etc.”. Assim, não responder a uma repórter, pode ser justificado pelo fato de ela ser mulher e, portanto, não merecer explicação sobre algo que ela, evidentemente, não dominaria. 
O questionamento à competência é uma constante e se reflete na tentativa das profissionais de se protegerem de situações de violência e assédio, exigindo posturas que estão além da questão de atuação profissional, como explica Schoch (2019, p. 31): "as mulheres jornalistas esportivas sentem que devem estar particularmente vigilantes quanto às suas atitudes, especialmente, para evitar certos estereótipos (sedutora, lésbica) que sentem na pele e devem negociar diversas tensões"6.

As mulheres lutam para conquistar seu espaço no mercado de trabalho, embora a legislação brasileira as ampare e exija, a partir da Consolidação das Leis Trabalhistas (CLT), de 1943, com artigos dispostos no Capítulo III que trata da Proteção do Trabalho da Mulher. (BRASIL, 1943). A Constituição Federal de 1988 proibiu a diferença de salários, de exercício de funções e de critério de admissão por motivo de sexo, idade, cor ou estado civil; (BRASIL, 1988) e a CLT sofreu alterações quando da aprovação da Lei n 9.799/1999, que buscou corrigir distorções quanto ao acesso ao mercado de trabalho ou à formação profissional das mulheres brasileiras. Em seu artigo 373A, a lei proíbe a publicação de anúncios de emprego com referência a sexo, idade, cor ou relação familiar; recusa de emprego ou promoção, e ainda demissão em razão de sexo, idade, cor, situação familiar ou estado de gravidez ${ }^{7}$ (BRASIL, 1999).

Ao tratar do direito do trabalho da mulher, a pesquisadora Léa Calil destacou a necessidade de se debater a questão da igualdade jurídica, entre trabalhadores e trabalhadoras, frente a desigualdade fática. Para ela, "o mecanismo para que mulheres tenham o mesmo tratamento que homens no mercado de trabalho, ao lado de uma efetiva ação sindical, é uma legislação eficaz." (CALIL, 2007, p. 119).

Como temos visto, o tratamento permanece diferente e as mudanças não têm se mostrado eficientes ao longo dos anos. Na década de 1930, a presença de mulheres nas redações era evidenciada na própria estrutura dos espaços - como conta José Hamilton Ribeiro:

As empresas jornalísticas eram pensadas e construídas como ambiente de sauna brega: só para homem. Nem havia banheiro feminino. No Estadão, à noite, quando fervia o trabalho jornalístico, as mulheres não eram aceitas nem na mesa telefônica. Havia mulheres como telefonistas, mas só durante o dia. À noite, um homem é que operava. Mulher podia ser telefonista, faxineira ou servia para fazer o café: circulava na área de serviço (RIBEIRO, 1998, p. 31).

O relato parece distante da realidade atual, mas ainda há espaços de prática esportiva (notadamente, estádios de futebol) em que não há banheiros femininos disponíveis para as profissionais - uma vez que atletas, comissões técnicas e arbitragem é, na quase totalidade, composta por homens. A tentativa de evitar situações de assédio leva as profissionais a reduzir a ingestão de líquidos ou mesmo prolongar por longos períodos necessidades fisiológicas, acarretando desconforto e, até mesmo, adoecimento.

\section{Deixa Ela Trabalhar}

Em 14 de fevereiro de 2018, a repórter Bruna Dealtry participava da transmissão, ao vivo, da partida Vasco da Gama e Universidad do Chile, pela Libertadores. Jornalista do canal de TV Esporte Interativo, Bruna foi beijada, à força, por um torcedor, durante a cobertura da partida. A reação da profissional, visivelmente constrangida, foi afirmar que agressão sofrida pelo torcedor do torcedor "não foi legal". A repórter continuou a transmissão. (REPÓRTER..., 2018).

Em Porto Alegre, três dias antes do caso de Bruna Dealtry, um torcedor do Inter agrediu, fisicamente e insultou a repórter Renata Medeiros, da Rádio Gaúcha, durante a cobertura do clássico de maior rivalidade no estado, entre Grêmio e Internacional. O torcedor do Inter gritou para a repórter: "sai daqui, sua puta". (GLOBOESPORTE.COM, 2018).

Os dois casos, infelizmente, não são isolados. Em 2016, após agressões verbais do cantor Biel, a uma repórter do Portal iG (MORAIS, 2016), profissionais lançaram uma hashtag - marcação que permite que as publicações sejam agrupadas e localizadas nas redes sociais - para denunciarem o caso: \#JornalistasContraOAssedio ${ }^{8}$. O movimento arrefeceu e, após os casos com as jornalistas esportivas, uma nova onda de protestos nas redes sociais chamaram a atenção do público, motivando um grupo de profissionais a se reunirem em um manifesto, a partir de um vídeo com duração de 2 minutos de 29 segundos, que mostra imagens com agressões, relatos e matérias jornalísticas que denunciam os casos, comentários ofensivos em redes sociais, com uma narração com vozes masculinas distorcidas que ofendem as jornalistas com palavrões, questionamentos sobre suas capacidades e profissionalismo (ROSSI, 2018). A seguir, profissionais da área se alternam nos dizeres que se seguem: 
Aconteceu comigo.

Recentemente, também aconteceu comigo.

Já aconteceu com todas nós...

E não dá mais pra acontecer.

Vagabunda, piranha...?

Isso não é normal.

Até quando?

Somos mulheres. E profissionais.

Só queremos trabalhar em paz.

O esporte também é lugar nosso.

Encosta em mim quem eu quero.

Quando eu quero.

No meu trabalho, ao meu trabalho...

Eu quero respeito.

Precisamos de respeito.

Merecemos respeito.

Respeito nos estádios, nas redações, nas ruas...

Respeito de torcedores, colegas, chefes...

Respeito de técnicos, jogadores e dirigentes.

Respeitem a nossa voz e as nossas escolhas.

Somos repórteres, comentaristas, jogadoras...

Bandeirinhas, árbitras.

E a gente está nessa já faz tempo.

E não vamos parar.

Vamos continuar ocupando nossos espaços.

Chega de desconfiança.

Chega de diferenciação.

Ei, você aí... homem... mulher...

Sociedade, autoridade.

Chegou a hora de se importar.

A omissão também machuca.

E juntos somos mais fortes.

Juntas somos invencíveis.

Não é engraçadinho.

Não é só machismo.

É desrespeitoso.

É nojento.

É ofensivo.

É uma violência.

É uma violência.

Chega (repete-se por várias vezes)

Deixa ela trabalhar (repete-se por várias vezes)

O vídeo é encerrado com uma tela preta e, em caracteres brancos, \#DeixaElaTrabalhar9 ${ }^{9}$ O manifesto, inicialmente contou com 52 mulheres jornalistas esportivas, transformou-se em um coletivo que passou a receber e denunciar casos semelhantes. O coletivo tem página no Facebook e perfis no Twitter (@ deixaelatrab) e Instagram (@deixaelatrabalhar).

O feminismo estaria vivendo, a partir da apropriação de ferramentas digitais, a chamada Quarta Onda:

Devido às peculiaridades da explosão do feminismo dentro desse contexto, já possível afirmar com segurança que estamos vivendo um momento de quarta onda do feminismo. Logo, já adiantamos que a quarta onda do feminismo é caracterizada principalmente pelo uso maciço das plataformas de redes sociais com fim de organização, articulação e propagação da ideia de que a igualdade entre os sexos ainda é uma ilusão. (SILVA, 2019, p. 377-378).

A velocidade e o alcance possibilitados pela internet - e, até então, inéditos - têm revolucionado e alterado a forma de demanda e, portanto, de circulação de mensagens, demandas e sentidos 
também. Com o desenvolvimento tecnológico, esses coletivos passaram a se apropriar do ambiente virtual para divulgar suas pautas.

Como explica, Silva: "assim, a quarta onda do feminismo surge mediante o avanço das tecnologias de informação e comunicação, sendo usadas para contestar a misoginia, o sexismo, a LGBTf́obia e vários tipos de desigualdades e violências de gênero" (SILVA, 2019).

Interessa-nos analisar, particularmente, como esse manifesto se apresenta ao público e como se dá a demanda por condições de trabalho, em meio a um ambiente tradicionalmente misógino, violento e sectário. $\mathrm{O}$ enunciado que nomeia o coletivo é, por si só, conflituoso. Uma vez que se afirmam profissionais, especialistas e, portanto, com legitimidade para o exercício das funções, lançam mão do verbo deixar para a demanda que deveria buscar equidade de direitos de trabalho. Ao enunciarem deixa ela trabalhar, apontam para o sentido de pedido de permissão para o exercício de um direito. Afinal, quem pode (ou não) deixar que elas trabalhem? A contradição posta no enunciado está marcada ainda no texto do vídeo-manifesto.

\section{SD1 \\ Somos mulheres. E profissionais. \\ Só queremos trabalhar em paz.}

Há a manifesta condição natural de ser mulher, apartada da questão profissional. Afinal, são jornalistas profissionais e a questão de gênero não deveria ser discutida, uma vez que o direito está posto. E, como vimos, assegurado pela CLT, referendado pela Constituição de 1988 e com distorções corrigidas a partir do Decreto-Lei no $3.199 / 1999$. Assim, mais que trabalhar em paz, essas profissionais têm amparo legal - não mencionado - para suas demandas. Nessa sequência discursiva, já são produzidos os sentidos que apontam para um poder maior que pode (ou não) dar paz e sossego, ao reconhecer que mais que mulheres, ali estão profissionais.

A legitimidade do trabalho dessas mulheres se materializa em enunciados como não é normal, chega de diferenciação, o esporte também é lugar nosso e vamos continuar ocupando nossos espaços. Entretanto, não há nenhuma menção à questão da equidade, da competência, da formação profissional, para além da legalidade, na presença nesses espaços.

Tomaremos como sequência discursiva a questão da ocupação do setor profissional. O manifesto, neste trecho, aponta para a legitimidade de seus direitos ao evocarem a questão histórica da luta de tantas outras mulheres pela possibilidade de exercer a atividade profissional destinada aos homens.

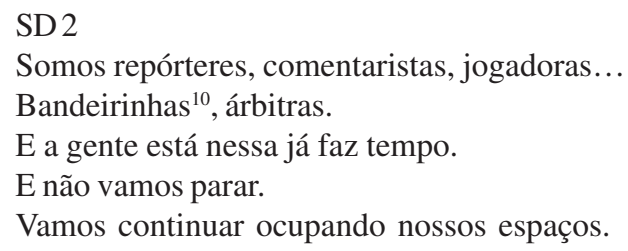

Os sentidos convocados aqui são os de presença em um território próprio, conquistado e mantido em um contínuo, algo processual. A partir da escolha do continuar ocupando - possível apenas para quem tem legitimidade (INDURSKY, 2006) - um espaço apresentado como delas. Neste momento, já não há mais o distanciamento que se dá no deixa ela trabalhar; ela uma outra, apartada das relações que excluem e retiram das trabalhadoras (elas mesmas) seus direitos. São mulheres repórteres, jogadoras, bandeirinhas e árbitras, em espaços profissionais que resultam de conquistas históricas. Nessa SD, evidenciam-se os sentidos de pertencimento e de luta coletiva por seus direitos. Luta essa anteriormente iniciada, presente e com a continuidade enunciada pelo não vamos parar.

Ao enunciarem que também são árbitras, o discurso se desloca para o sentido de apropriação de um termo que passa a concordar em gênero a partir da presença de mulheres na função. Uma vez que o substantivo árbitro era, na Língua Portuguesa, tomado para homens e mulheres - em mais um caso em que a ocorrência altera o uso ${ }^{11}$ do termo.

Assim, o manifesto conclama todas e todos a uma causa legítima e que necessita da adesão de segmentos variados, uma vez que o assédio - tomado com falta de respeito - é sofrido entre torcedores, colegas, chefes, técnicos, jogadores e dirigentes, em uma ampla denúncia dos espaços e personagens dessa violência; além do silenciamento a outros casos de assédio. Como nos explica Orlandi, o silêncio "recorta o dizer [e] como o sentido é sempre produzido de um lugar, a partir de uma posição do sujeito - ao dizer, ele estará, necessariamente, não dizendo 'outros' sentidos” (2002, p. 55). Assim, o 
manifesto lança luz aos casos que, por tanto tempo, foram silenciados nesses ambientes, naturalizados como parte de uma lógica inquestionável.

\author{
SD3 \\ Ei, você aí... homem... mulher... \\ Sociedade, autoridade. \\ Chegou a hora de se importar. \\ A omissão também machuca.
}

O funcionamento enunciativo é de resposta à violência sofrida, constantemente, por essas mulheres que, ora se identificam com o discurso e sua posição-sujeito que enunciam o direito ao trabalho, ora se desidentificam com esse discurso e se afastam como se já não fossem mais enunciadoras de um clamor de sua representação coletiva. A não associação a uma luta maior - de classe e gênero - é evidenciada ao não reconhecerem a autoria dos casos de assédio como reflexo da misoginia e do funcionamento de uma sociedade patriarcal. Ao não tipificarem a violência sofrida, corroboram com o discurso que sustenta que a queixa é vitimismo de feministas que veem machismo em todos os setores. Naquilo que não passa de uma brincadeira, de um gracejo, de uma cantada... O discurso dominante aponta essas práticas como valorização da mulher pelo homem, e não machismo. A contradição está posta ao afirmarem que:

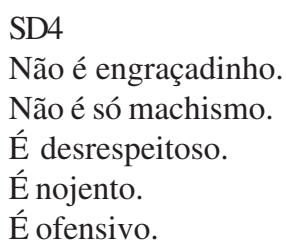

Pois bem, é ofensivo, nojento, desrespeitoso, sim. E é machismo. O deslizamento de sentidos que, ao contrário da negativa, apenas corroboram com a conclusão de que essas são práticas machistas, apontam para a tentativa de se distanciar do que os machistas irão classificar de mimimi de feministas feminazis, em alusão às mulheres "extremistas" na luta pelos direitos das mulheres - em alusão à reclamação sem conteúdo, expressão constantemente atribuída às minorias que fariam barulho (o tal mimimi) sem argumentos, infantilizando exigências legítimas desses grupos marginalizados na/pela sociedade, as reduzindo a simples queixumes.

\title{
Considerações finais
}

As mulheres permanecem lutando pela efetivação de direitos, mesmo que formalmente adquiridos, em campos diversos, notadamente no do trabalho. A distância entre mulheres e homens está em salários, acesso a empregos, formação profissional, promoção, reconhecimento, cargos de chefia etc. O teto de vidro que não permite a ascensão das mulheres - embora ninguém o veja, ele está sempre lá - ainda é mais impeditivo em funções e campos mantidos, décadas após década como espaços de domínio masculino, ou, popularmente falando: coisa de homem.

A luta das mulheres jornalistas esportivas que, como vimos, se contradizem em seu discurso pelo legítimo direito ao trabalho, aponta para contradições da própria sociedade que ainda segmenta o mercado de trabalho com forte ancoragem patriarcal, determinando às mulheres espaços nos quais podem ou não podem ser aceita a sua presença.

A violência sexista a que essas trabalhadoras são submetidas, denunciam e voltam a sofrê-la, clama por ações que discutam o direito para além dos textos de lei, e sim para uma educação ampla que conscientize homens - e mulheres também - que o espaço de trabalho não é uma concessão de um grupo que detém o (e se impõe no) poder. Para que não haja a continuidade do funcionamento discursivo que, mesmo demandando um direito, é preciso pedir para que as deixem - que as permitam - trabalhar.

As mulheres deverão ser notícia, produzir notícia, redigir notícia, narrar, reportar, apresentar e comentar eventos das mais diversas abordagens. Deverão ter a liberdade (direito democrático) de serem quem são, como assim nasceram, como tenham se constituído social e politicamente, como escolheram ou como foram chamadas a viver. A luta só se amplia com a tomada de pautas de grupos de invisibilizadas - sejam elas negras, indígenas, lésbicas, trans... enfim, mulheres. 


\section{Referências}

ASSOCIAÇÃO BRASILEIRA DE JORNALISMO INVESTIGATIVO. Mulheres no jornalismo brasileiro. São Paulo: Abraji, 2017. Disponível em: http://www.mulheresnojornalismo.org.br/12901_GN_relatorioV4.pdf. Acesso em: 13 out. 2019.

BRASIL. Constituição (1988). Constituição da República Federativa do Brasil. Brasília, 1988.

BRASIL. Decreto-Lei n. 5.452, de $1^{\circ}$ de maio de 1943. Aprova a Consolidação das Leis do Trabalho. Rio de Janeiro, 1943.

BRASIL. Decreto-Lei n. 3.199, de 14 de abril de 1941. Estabelece as bases de organização dos desportos em todo o país. Rio de Janeiro. 1941.

BRASIL. Lei n. 9.799, de 26 de maio de 1999. Insere na Consolidação das Leis do Trabalho regras sobre o acesso da mulher ao mercado de trabalho e dá outras providências. Brasília, 1999.

CALIL, L. E. Direito do trabalho da mulher: a questão da igualdade jurídica ante a desigualdade fática. São Paulo: LTr, 2007.

CARNEIRO, S. Mulheres em movimento. Estudos Avançados, v. 17, n. 49, p. 117-133, set/dez. 2003.

GLOBOESPORTE.COM. Repórter grava agressão em Gre-Nal e registra boletim de ocorrência. Globo Esporte, Porto Alegre, 11 mar. 2019. Disponível em: https://globoesporte.globo.com/rs/futebol/noticia/reporter-grava-agressao-em-gre-nal-e-registra-boletim-deocorrencia.ghtml. Acesso em: 3 mar. 2020.

GOODMAN, M. Eighty Days: Nellie Bly and Elizabeth Bisland's history - making race around the World. Nova Iorque: Ballantine Books, 2013.

GOODMAN, M. Eighty days: Nellie Bly and Elizabeth Bisland's history-making race around the world. New York: Ballantine Books, 2013.

INDURSKY, F. Identificação e contra-identificação: diferentes modalidades de subjetivação no discurso do/sobre e MST. In: MARIANI, B. (org.). A escrita e os escritos: reflexões em análise do discurso e psicanálise. São Carlos, SP, Clara Luz, 2006.

'MENINO veste azul e menina veste rosa', diz Damares Alves. Folha de S. Paulo, São Paulo, 3 jan. 2019. Disponível em: https:// www1.folha.uol.com.br/poder/2019/01/menino-veste-azul-e-menina-veste-rosa-diz-damares.shtml Acesso em: 3 abril de 2020.

MORAIS, P. Biel chama repórter de "gostosinha" em entrevista e diz que a "quebraria no meio". Portal Ig, 9 jun. 2016. Disponível em: https://delas.ig.com.br/comportamento/2016-06-03/biel-chama-reporter-de-gostosa-em-entrevista-e-diz-que-a-quebraria-no-meio.html. Acesso em: 3 mar. 2020.

ORLANDI, E. As formas do silêncio: no movimento dos sentidos. 5. ed. Campinas, SP: Editora da UNICAMP, 2002.

ORLANDI, E. Discurso em análise: sujeito, sentido e ideologia. 2. ed. Campinas, SP: Pontes, 2012.

REPÓRTER DE TV É ASSEDIADA EM TRANSMISSÃO DE JOGO DO VASCO. Veja, [São Paulo], 14 mar. 2018. Disponível em: https://veja.abril.com.br/placar/reporter-de-tv-e-assediada-em-transmissao-de-jogo-do-vasco/. Acesso em: 3 mar. 2020.

RIBEIRO, J. H. Jornalistas: 1937 a 1997: história da imprensa de São Paulo vista pelos que batalham laudas (terminais), câmeras e microfones. São Paulo: Imprensa Oficial do Estado, 1998.

ROSSI, M. \#DeixaElaTrabalhar: a nova investida de mulheres jornalistas contra o machismo. El Pais, São Paulo, 25 mar. 2018. Disponível em: https://brasil.elpais.com/brasil/2018/03/23/politica/1521823054_844544.html. Acesso em: 3 mar. 2020.

SARAIVA, L. A. S. Além dos estigmas profissionais. In: FREITAS, M. E.; DANTAS, M. (Org.). Diversidade sexual e trabalho. São Paulo: Cengage, 2012.

SCHOCH, L. Stéréotypes de genre. Sur le journalisme, v. 8, n. 2, dez. de 2019. Disponível em: http://www.surlejournalisme.kinghost.net/ rev/index.php/slj/article/view/400. Acesso em: 05 jan. 2020.

SCHOCH, L; OHL, F. Women sports journalists in Switzerland: between assignment and negotiation of roles. Sociology of Sport Journal, n. 28, p. 189-208, 2011.

SILVA, G. C. Mulheres impedidas: a proibição do futebol feminino na imprensa de São Paulo. Rio de Janeiro: Multifoco, 2017.

SILVA, J. M. Feminismo na atualidade: a formação da quarta onda. Recife: Independently Published, 2019.

SOUZA-LOBO, E. A classe operária tem dois sexos: trabalho, dominação e resistência. São Paulo: Perseu Abramo; Brasiliense, 2011.

\section{Notas}

1 A jornada da jornalista estado-unidense foi contata por Matthew Goodman e é pouco conhecida, inclusive por outras jornalistas.

2 Lógica sintetizada pela ministra da Mulher, Família e Direitos Humanos, Damares Alves, em 02 de janeiro de 2019: “Atenção, atenção. É uma nova era no Brasil. Menino veste azul e menina veste rosa”, proferida durante cerimônia de transmissão de cargos no ministério. ("MENINO veste azul e menina veste rosa', diz Damares Alves, 2019).

3 Neste artigo, não estamos nos detendo nas relações para além do binarismo de gênero homem x mulher, embora reconheçamos que as relações, no mercado de trabalho, são ainda mais estigmatizadas na presença de LGBTQI+, (SARAIVA, 2012), como também nas relações patriarcais e racistas as quais estão submetidas mulheres negras (CARNEIRO, 2003).

4 “Dans le sport, tout comme d'autres domaines comme la politique ou la guerre qui sont pensés comme «masculins» [...] restent globalement des bastions masculins des médias dans de nombreux pays [...] notamment le cas dans les sports de traditiontradition masculine comme le football, le baseball ou le hockey sur glace". 
5 "The number of women who have entered sports journalism, a traditionally male domain, is lower and it largely remains a male-dominated".

6 “Les femmes journalistes de sport ont le sentiment de devoir être particulièrement vigilante's quant à 'leurs attitudes, notamment pour éviter certains stéréotypes (séductrice, lesbienne) dont elles se sentent facilement affublées et de devoir négocier diverses tensions “.

7 A legislação sofreu alterações após a aprovação, em 2017, da Reforma Trabalhista, sancionada pelo então presidente Michel Temer, com retrocessos que atingem a proteção de trabalhadores e trabalhadoras, especificamente, no que concerne às modificações trazidas em relação a intervalos, jornadas, trabalhos em locais insalubres.

8 A profissional, então com 21 anos, foi chamada de gostosinh a pelo cantor que afirmou que a quebraria no meio se mantivessem relações sexuais e a teria chamado de cuzona ao exigir que a repórter atendesse seu celular, durante a entrevista. A repórter foi demitida um mês após a agressão. (MORAIS, 2016)

9 A então mestranda Janaina Alves Pereira Almeida dos Santos apresentou a análise "A relação política-discurso no enunciado da campanha \#DeixaElaTrabalhar" como trabalho final da disciplina “Estudos em Sujeito, Discurso e Práticas Sociais na linha Análise do Discurso", no PPGLL/ UFAL.

10 O termo bandeirinha é um sinônimo popularmente conhecido para os auxiliares da arbitragem ou árbitros de linha, nos jogos de futebol.

11 Com a chegada da primeira mulher à Presidência da República, no Brasil, o substantivo presidenta passou a ser de uso corrente, em documentos, no noticiário e no diaa dia da população, embora com polêmica e uso atribuído a pessoas ligadas a partidos e movimentos de esquerda.

\section{Lídia Ramires}

lidia.ramires@ichca.ufal.br

Doutorado pelo Programa de Pós-Graduação em Linguística e Literatura (UFAL)

Professora do Curso de Jornalismo (UFAL)

\section{UFAL}

Av. Lourival Melo Mota, S/N, Tabuleiro do Martins,

Maceió - AL

CEP: 57072-970

\author{
Agência financiadora \\ Não se aplica. \\ Contribuições da autora \\ Não se aplica.
}

\author{
Consentimento para publicação \\ Não se aplica.
}

\section{Conflito de interesses}

Não há conflito de interesses.

Aprovação por Comitê de Ética e consentimento para participação

Não se aplica. 